\title{
Erratum to: Feeding selectivity in larvae of the European hake (Merluccius merluccius) in relation to ontogeny and visual capabilities
}

Elvira Morote • María Pilar Olivar •

Anna Bozzano · Fernando Villate · Ibon Uriarte

Published online: 26 March 2011

(C) Springer-Verlag 2011

\section{Erratum to: Mar Biol}

DOI 10.1007/s00227-011-1654-2

The second sentence of the last paragraph "In summary ... study area" before acknowledgments should read as "This pattern is evident from the early stages in this species and shows no change as larvae grow, indicating that they are skilled predators due to the high degree of development of their feeding-related structures".

The online version of the original article can be found under doi:10.1007/s00227-011-1654-2.

E. Morote $(\bowtie) \cdot$ M. P. Olivar · A. Bozzano Institut de Ciències del Mar (CSIC), Passeig Marítim de la, Barceloneta 37-49, 08003 Barcelona, Spain

e-mail: morote@icm.csic.es

F. Villate

Department of Plant Biology and Ecology, University

of the Basque Country, Barrio Sarriena s/n,

48940 Leioa, Spain

I. Uriarte

Department of Plant Biology and Ecology,

Faculty of Pharmacy, University of the Basque Country,

Paseo de la Universidad 7, 01006 Gasteiz, Spain 